\title{
Developing a Planned Intervention Using the Behavior Change Model to Improve Self-control of Healthcare Employees: A Longitudinal Study
}

saeed Hameed aldulaimi ( $\sim$ sskw20@yahoo.com )

Applied science university https://orcid.org/0000-0003-1131-5633

Marwan Mohamed Abdeldayem

ASU

Mohamed Noureldin A. Abdelhakim

UMS

\section{Research}

Keywords: Planned Intervention, Change Management, Behavior Change Model, Self-Control, Healthcare, Human Resources, Kingdom of Bahrain

Posted Date: July 8th, 2020

DOl: https://doi.org/10.21203/rs.3.rs-37380/v1

License: (a) (1) This work is licensed under a Creative Commons Attribution 4.0 International License. Read Full License 


\section{Abstract \\ Background}

The purpose of this study is to develop a planned intervention in the health care sector in Bahrain to improve self-control of healthcare' employees by using the new method for characterizing and designing behavior change i.e. the Behavioral Change Wheel (BCW). Hence, the study is applying a longitudinal methodology in the healthcare sector in the Kingdom of Bahrain for a sample of 64 participants over three-month period (from November 2019 to January 2020).

\section{Methods}

Procedures of this planned change task went through three stages based on Kurt Lewin change field theory, Stage 1: pre-assessment of employees' self-control using the Brief Self Control Scale (BSCS) questionnaire. Stage 2: planned intervention via employing the Behavioral Change Wheel (BCW) as a new method of change. Stage 3: post assessment was conducted by repeating the self-control measurement, then comparing the new results with the previous ones.

\section{Results}

The findings reveal that the 13-Items of Brief Self-Control Scale (BSCS) provided different results over the three stages of the study. In stage 1 (pre-assessment) self-control level was low, while the result show optimization of self-control in stage 3 (post assessment).

\section{Conclusion}

This study adds to the body of knowledge by developing and validating a new model in change human behavior i.e. the change behavior stages (CBS) model. Practically, this study is one of its kind to apply the Brief Self Control Scale (BSCS) and the Behavioral Change Wheel (BCW) in health sector in the Middle East. The BCW has been also confirmed as a "valid" and "reliable" instrument that can be utilized by future researchers to improve human behavior in organizations.

\section{Background}

Admittedly, technology advancements converted the rhythm of life to become faster and give feeling to people as pressures by sources of communication surround them [1]. In the east of the world, it is more obvious through the increased tensions and low ability to afford and resist pressure by developing selfcontrol that can deal professionally to maintain positive behavior. Patience and self-control are the key to successfully deal with those sources of pressure. Patience is a kind of owning self instead of let others control it. The power of patience giving individuals the capacity to treat pressures professionally and let 
the mind control the physical and psychological parts of the human. The words of patience and selfcontrol are used interchangeably which is leading to make the individuals decision more rationale and reasonable.

It may be extremely difficult to make and maintain changes in areas related to temper control, behavior over a long period of time. This type of change often requires a more severe form of stimulation and education, such as behavior change programs. Based on Social Cognitive Theory, a person is not like a machine, responding automatically to a specific input. People have the capability to symbolize, selfregulate, and self-reflect [2]. Thus, business owners must bear in mind that in order to have a long-term change in behavior, programs must include effective support programs, in addition to positive incentives, and continuous follow-up of individuals involved in such programs. Also, as part of behavioral change programs, staff should be taught how to maintain new healthy behavior over a long period of time. For many individuals, this new behavior will become a new healthy habit. Support from coworkers, family and friends can also be essential to help employees succeed.

An essential component of employee well-being in work is known as behavior change programs. In this case, the employees make noticeable and lasting changes to the behaviors that affect their inspiration and motivation in workplace. [3], observed that in most successful change efforts aims to meet shared goals, leaders focus on connecting with people's emotions because it will spark the behavior change and actions that lead to success. Employees at time of change must be presented with evidence that makes them feel inspired to achieve goals, and perhaps look at the problem, a spark of hope for a solution, or a deep reflection on current habits, and whatever it is, but something that moves them on the emotional level.

I argue that will-power is

essential also to a certain form of self-control

I argue that will-power is essential not just to what Holton

calls 'strength of will', but also to a certain form of self-control.

Control of the human behavior, feelings and reaction is responsible for the success and failure in life. IQ alone is no longer the measure for success; It only counts for $20 \%$ of success, and the rest goes for emotional and social intelligences, and luck [4]. Ethics also can help in self-discipline in which people have belief in the ability to control oneself and self-confidence let people realize their abilities to achieve what they want and what they believe in, and then give the power to control the current moment [5]. Selfmonitoring as this is a form of self-reaction with the aim of making a change. [6] reported that "being under high levels of stress means that our bodies' energy is used up in acting instinctively and making decisions based on short-term outcomes, therefore, people need to increase the capacity for pressure by learning how to manage stress". Therefore, employees with motivation in achieving the goals, as the greater the desire to make efforts, the more likely it is to succeed. The studies confirmed that self- 
affirmation could help people to have more self-control as well as improving attention, focus, stress management, and self-awareness. According to [4] emotional intelligence consists of five components: Knowing our emotions (self-awareness), managing them, motivating ourselves, recognizing emotions in others (empathy), and handling relationships. [6] suggests that self-control can even give fast results to identifying personal issues arising from the experience; pinpointing personal intentions; empathizing with others in the experience; recognizing one's own values and beliefs; linking this experience with previous experiences; creating new options for future behavior; looking at ways to improve working with patients, families, and staff in order to meet patients' needs.

In general, self-control can ensure that individual have the energy to work and life can feel overwhelming. In fact, the lack of care of the healthcare employees toward the patients may lead to managerial and technical problems. People come to hospitals with exceptional situation and need compassion behavior from hospital stuff, which come from the wellbeing of employee and their readiness to absorb the patient anxiety.

The rest of this paper is organized as follows: conceptual framework is presented in Sect. (2). Section (3) introduces the methodology and design of the study. Discussion and results of statistical analysis are explained in Sect. (4), while conclusions are in Sect. (5).

This study stands on plethora of theories and change management model that found valid in changing human behavior. The Transtheoretical Model [7] provide an understanding of individuals' behavioral changes and describing how people move dynamically through five different stages of behavioral changes. The TTM has been widely used to describe and understand exercise behavior, such as adoption and maintenance of physical activity (PA) [8]. The four core constructs of TTM are stages of change, selfefficacy, decisional balance, processes of change, and levels of change. The TTM holds that people begin to perceive more benefits than disadvantages from adopting positive behavior changes as they move through the later stages [8]. This view was also supported by [9], who stated that the cons outweigh the pros in the earlier pre-contemplation stage of change. In this study, the pros and cons in decisional balance construct refer to the benefit that encourage people to exercise and barriers that refrain people to act.

Moreover, the theory of planned behavior [10], [11] was developed from the theory of reasoned action, and is more applicable when the probability of success and actual control over performance of a behavior are suboptimal. The theory was intended to explain all behaviors over which people have the ability to exert self-control.

[12], has proposed a multistage process of planned change divided the process of change into three stages: (1) Unfreezing Stage: Kurt Lewin sees through field studies that organizations that have been able to withstand and excel and achieve the required change have taken the time to effect effective change and did not follow the policy of burning stages; because this leads to unforeseen results and therefore it must be considered some criteria when doing this process. (2) Changing Process: after the diagnostic process, the organization seeks at this stage to support a homogeneous team of ideas and goals in order 
to implement its reform approach, which is to make changes at the level of the organizational structure, such as canceling some organizational units, or merging them and the changes may affect the powers and responsibilities of employees, or aim to spread new values or adopt modern technology that contributes to the use of new methods of work in order to ensure the continuity of the successful performance of the tasks of the institution. (3) The Refreezing phase of installation and consolidation the organization seeks to maintain the gains and the level of performance that has arisen from the previous stages by protecting it from any new exhibitor by establishing a monitoring and follow-up committee that assesses the results of the change process [12].

This study intends to conduct an experimental work by observing employee behavior in their job, as they are staff members in a public hospital in Bahrain. Then, assess the participants' behavior to determine level of self-control based on their feedback. After accomplishing first assessment of self-control, employees will undergo a planned change process to develop their ability of self-control by applying Michi et al model [13], which is, consist of several stages. Figures (1) below illustrates the change behavior stages (CBS) model as a conceptual framework of the study:

Hence, this study intends to achieve four objectives as follows:

1. Identify the current self-control level of employees.

2. Arrange interventions and have development plan using change behavior model including few courses and workshops to ensure that employees learn new techniques of self-control. This process probably takes several weeks until they absorb and apply what they learned in a course of action.

3. Changing a desired behavior needs panned change behavior and it takes long time and process therefore, this study aims to pave the way to translate the theory to practice by examining the change model and ensure the development of self-control behavior. In addition, to suggest a fruitful step that make useful recommendations in designing and applying change intervention.

4. Re-use the measurement tool to re-assess the participants' self-control in order to estimate their level of self-control post the process of development.

Accordingly, three questions have been generated to be answered as follows:

1. What is the current level of employees' self-control?

2. Will the people of self-control can be developed through planned change behavior?

3. What is the post level of employees' self-control?

\section{Methods}

Handling a social phenomenon requires action field research according to scientific foundations. So that the study is subject to a scientific method, which in turn depends on scientifically designed field tools and these research tools help the researchers in either collecting information or transferring the results into useful outcomes [14], [15]. 
This research uses longitudinal method with an examination of the level of self-control. The measurement of longitudinal change, however, has been a long-standing and controversial topic [16], [17]. Longitudinal data is essential to investigate changes in individuals within the population as well as assessing all effects. As scholars specified, in longitudinal research data collected at a particular point of time then, emphasizing the change and containing at minimum three repeated observations on at least one of the substantive constructs of interest. However, the minimum number of repeated measures for a longitudinal design is three, but more than three is better [18].

There are several advantages of the longitudinal method; as it monitors carefully any growth increase using the growth curves. It allows analysis of aspects of growth to be accurate and provides an opportunity to know the effects of environmental and cultural variables on behavior and personality. It provides an opportunity to analyze the relationships between operations.

\section{Measures}

The study adopted the questionnaire survey of Tangney et al. [19] to estimate the primary level of individuals' behavior with regard to self-control behavior in particular. Hence, the 13-Items of Brief SelfControl Scale (BSCS) were used in this research effort. Worth mentioning that the reliability and validation of these questions have been tested in several previous studies

\section{Participants}

As mentioned earlier, the study included two sections of a public hospital in Bahrain, namely the Patient Registration Department and the Patient Reception Section, totaling 64 employees. The number of those who participated in the study along its length after removing the names of individuals who could not participate due to the entire period of study in addition to their special circumstances and their inability to continue to work for the duration of the study. The participants are voluntarily accepted to cooperate to do this experiment with encouragement from HR department in the hospital. All 64 participants are Bahraini (40 females and 24 males). This longitudinal study was a three-month experiment from November 2019 until January 2020.

In order to maintain participants' privacy, the study tries to fulfill its moral promise to preserve information revealed from the participants. Although the study conducted an agreement with the Human Resources Department and with its permission, the specificity of the names of individuals working and participating in this research effort is not subject to publicity.

\section{Procedures}

Following Kurt Lewin model, this study will conduct multistage process of planned change dividing the process of change into three stages: 
Stage 1: participants have been asked to give their feedback in term of self-control according the questionnaire of Tangney et al. which includes 13 questions with a five points scale from 1-5. Even though, the previous studies confirmed that when participants asked to provide their feedback in a shape of survey, they show themselves in ideal way. However, this study with adequate number of respondents can reach accepted level of reliability [20].

Stage 2: according to the change field theory of Lewin, at the second stage of change, the individual learns new ideas, methods, skills and knowledge. So that the individual behaves in a new manner or performs his work in a new way, meaning that at this stage an actual change and amendment are made in the duties, tasks, performance, techniques, or organizational structure, and further Lewin warns from rushing to take this stage and changing things at an unreasonable speed, because that would lead to the emergence of resistance to changing the current situation, accompanied by confusion and a mixture of feeling safe and anxious. To make change happens, this study stands on the Behavioral Change Wheel (BCW) as a new method of change that designed by Michie et al. [13].The researchers worked closely with the participants through coordination with the HR in the hospital. The researchers did what is the necessary activities and suggested to the HR to conduct other training activities that were going in line with the process of the changing behavior model as mentioned above. First month was focusing on developing the employees' capabilities; second and third month were focusing on opportunity and motivation in parallel.

Stage 3: after three months of hard working (i.e. from November 2019 until January 2020) to implement the changing task, the researchers believed that it is time to move to the third stage of change. Refreezing stage according to Lewin [12], aims to stabilize change by helping individuals integrate the attitudes, ideas and behavior patterns they have learned into their usual working methods, and modern methods become easy, satisfactory, and reinforcement. Furthermore, additional training and enhancement of stability can be used in this stage. The process of re-estimating the self-control behavior by repeating the self-control measurement, then compare the new results with the previous ones.

\section{Data Collection And Analysis}

This study adopts the BSCS questionnaire of Tangney et al. [19]. Table (1) below presents the demographic profile of the participants of this research effort. This questionnaire is considered the main reliable source for data collection to measure the Self-Control of participants. It has been designed in line with the nature of the research and the type of data and information required. The questionnaire was distributed to the participating individuals to obtain their answers about the questions related to the selfcontrol behavior of 64 employees. Since the questions are short and related to self-behavior, the questionnaire papers were collected upon completion by coordination with human resources department in the hospital. When initiating a preliminary analysis of the data, the results of the high reliability of the level of self-control behavior were revealed. Through observing the behavior of workers with the auditors, the researchers found out the truth of the problem that lies in the level of employees' self-control and their 
resort to behaviors out of control and engage in conflicts with the beneficiaries of the hospital review. Thus, it was necessary to know the period of control of individuals before starting the process of change and the development of their performance. Preliminary data collected from the respondents relate to determining the level of self-control and the ability of individuals to control their behavior during work to obtain clear consistency in the positivity of the behavior they exhibit while performing work tasks. Since the study uses a questionnaire that was employed in several previous studies and has proven widely credible, the data collected was entered into the statistics software SPSS in order to measure the descriptive statistics. Several commonly used measures to explain the characteristics of a set of data such as the mean, mode, minimum, max, variance, and standard deviation as shown in table (1) below.

Table 1

Self-Control Results

\begin{tabular}{|ll|lll|}
\hline \multicolumn{2}{|c}{ Item Statement } & m & SD & Level \\
\hline 1 & I am good at resisting temptation. & 2.4 & 1.1 & Bad \\
\hline 2 & I have a hard time breaking bad habits. & 3.4 & .98 & Bad \\
\hline 3 & I say inappropriate things. & 3.4 & 1.06 & Moderate \\
\hline 4 & I do certain things that are bad for me, if they are fun. & 4.2 & 1.59 & Bad \\
\hline 5 & I wish I had more self-discipline. & 4.1 & 1.03 & Bad \\
\hline 6 & Pleasure and fun sometimes keep me from getting work done. & 4.5 & 2.59 & Bad \\
\hline 7 & I have trouble concentrating. & 3.8 & 1.56 & Moderate \\
\hline 8 & I am able to work effectively toward long-term goals. & 1.9 & 0.94 & Bad+ \\
\hline 9 & $\begin{array}{l}\text { Sometimes I cannot stop myself from doing something, even if I } \\
\text { know it is wrong. }\end{array}$ & 4.8 & 2.6 & Bad+ \\
\hline 11 & I refuse things that are bad for me. & 3.7 & 2.5 & Moderate \\
\hline 12 & People would say that I have iron self-discipline. & 1.4 & 0.52 & Bad \\
\hline 13 & I often act without thinking through all the alternatives. & 2.8 & 1.67 & Bad \\
\hline
\end{tabular}

\section{Results}

Descriptive statistics are presented in table (2). It can be seen that 64 employees participated in this study. Majority of them are female (62\%). According to age, the largest percentage (50\%) is between $30-$ 39 years old. Regarding the level of education, $57 \%$ of the participants have bachelor degree. As for the years of experience, $45 \%$ of participants are having experience between $1-5$ years. 
Table 2

demographic profile of the participants

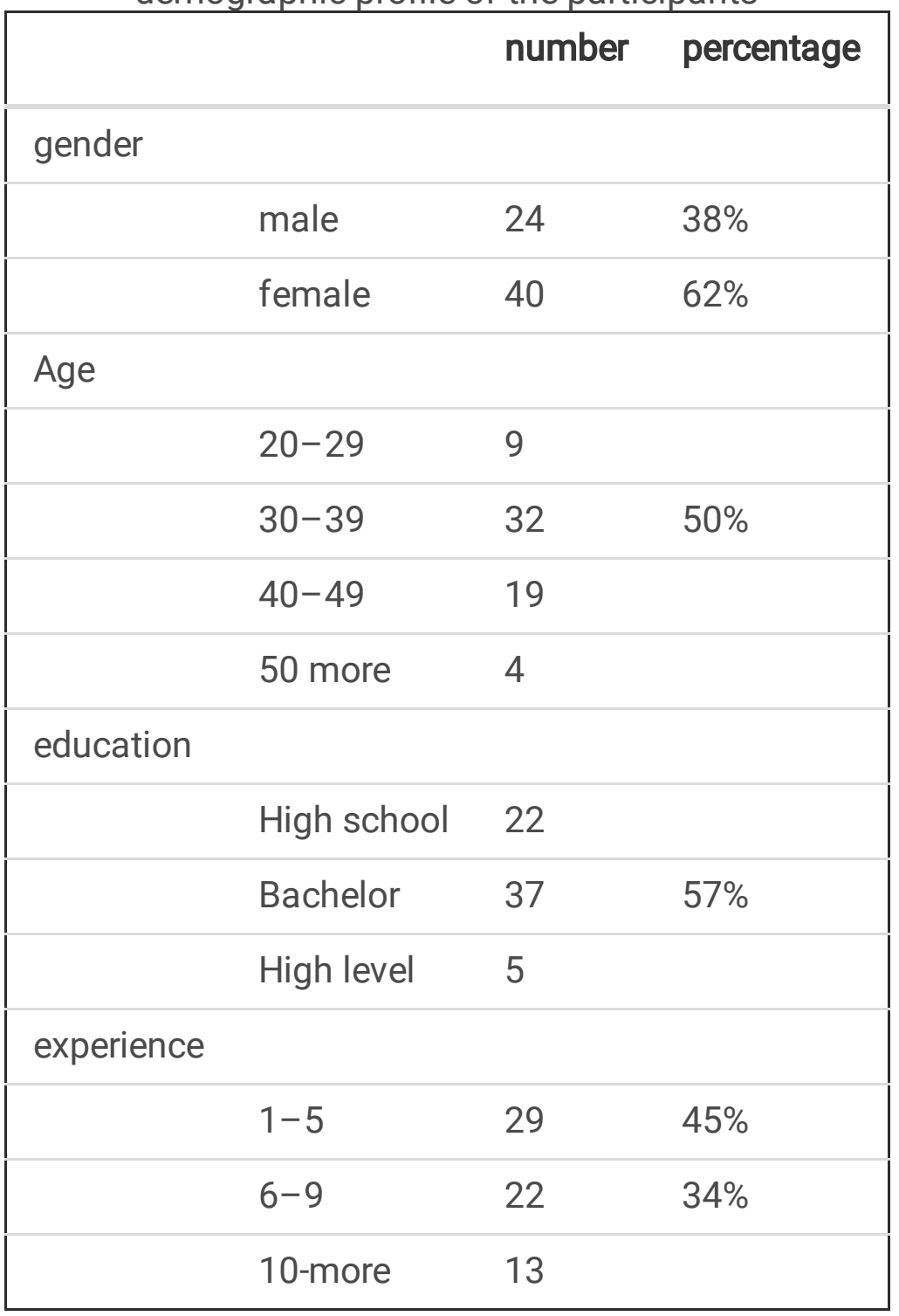

Further, Participants rated how well statements describe them (i.e. "I am good at resisting temptation") on a 5-point scale. The BSCS demonstrated good reliability in the current sample $(a=.90)$. Measuring the targeted behavior aims to record the frequency of the behavior or the duration of its occurrence, to judge later the success of the behavior modification plan. It should be noted here that behavior modification is a continuous process that includes measurement in the pre-treatment baseline stage / during treatment / and the post-treatment phase (follow-up). The most famous method of measurement is recording of repeated behavior: It is the measuring of the level of behavior occurs in a specific period, and on average, that period is determined in this study as three months.

\section{Employing Behavioral Change Intervention}

The process of redesigning the employees' behavior started firstly to adopt the adequate model that ensure the desired results. This study decided to adopt the Behavioral Change Wheel (BCW). The 
employees diagnosed that they have quite low level of self-control, therefore, the team of this research intend to intervene as developers to convert this behavior and make the necessary change. We believe that this is the first attempt to undertake a systematic analysis of behavior intervention frameworks and apply useful criteria to them. The study used an efficient method of choosing the kinds of intervention that are likely to be appropriate for a given behavioral target in a given context and a given population. This study adopts the BCW model, which consists from three main components (i.e. capability, opportunity, and motivation) - as shown in figure (2) below- that may interact to generate behavior that in turn influence these components

The first step in the process is motivation which defined as brain processes that energizes and direct behavior [21]. [22], defines learning motivation: as the desire of learners to work or participate in continuous learning and take responsibility for their own development. Capability is defined as the individual's psychological and physical capacity to engage in the activity concerned[13], where opportunity can be taken to mean all the factors that lie outside the individual that make the behavior possible.

To build a comprehensive approach of implementation of change behavior according to the BCW model, we used 9 interventions functions as it is adequate techniques to ensure development of behavior and in particular self-control. They are respectively as follows: Education, Persuasion, Incentivisation, Coercion, Training, Restriction, Environmental restructuring, Modelling, Enablement. See figure (2) that shows the components of BCW model.

\section{Motivation}

The first action was to increase employees' motivation because motivation is extremely important in the field of change behavior, and it is crucial in building and integrating personality and determining the types of human behavior. The beginning was to explain the purpose of this process because any activity cannot occur unless it has a goal and meaning that it seeks to achieve and satisfy this goal. The human being is a living being capable of performing a wide variety of behaviors such as perception. Motivation is what motivates membership to perform these behaviors and motivates them to perform a specific activity [23].

In the first month (i.e. November 2019), we worked with employees to teach them to elevate their knowledge of motivation. Motivation contributes to natural, emotional, and cognitive changes in the individual, in terms of understanding, attention, remembering and forgetting, or through their effect on thinking and learning [24]. The concept of motivation helps us explain individuals' differences in work achievement when these differences are due to factors other than intelligence. [25], notes that motivation is a concept that includes all motivations. He indicated that there are two types of motivation: Internal motivation: that is, people are driven internally by subjective factors or present in the task they perform and External motivation: in which people are driven externally as a result of factors outside themselves in order to obtain reinforcement from behind their implementation of some activities. 
It was great opportunity for employees to learning about motivation, given that motivation is internal or external situations of the organism. As for the motivation of self-control, it is a special case of motivation that refers to an internal state of the worker, which leads it to pay attention to the task situation, accept it with targeted activity, and continue it until it is achieved. According to the Skinner scientist's procedural conditioning theory, human beings, like all other animals, are a catalyst for producing enhanced behaviors from the environment and avoiding punishing behaviors. Thus, the internal state of membership is affected by boosters. It is interested in internal and external factors, observation and interpretation of the causes of behavior, as it is a source of energy humankind extends behavior, elicits its activity, and directs it toward specific goals. Hence, to develop the motivation as it plays an important role in learning, and represents the desire to learn, know, understand, process information, formulate problems and solve them; the following three factors were used to develop motivation and the individuals' previous experiences also play an important role in its development and growth.

1. Coercion: it means the ability to make to pressure to enforce the employees to act in certain way. It is possible to consider coercive as form of power which it comes from rules and law in our case. Employees participated in this empirical study understand carefully that it is important to act patiently in work to ensure they have peaceful job. Employees they expect that following the rule is compulsory therefore, it is better to prepare them to have the right skills to behave professionally. Furthermore, employee must feel what they lose and what the cost of not being patient is. To let them imagine the consequences probably happen in future will help them to change.

2. Training and experimentation: [26], define the Training as the "method for providing workers with skills." and technical knowledge in a specific field and its aim is to increase. The effectiveness, efficiency and investment of workers in their workplaces a good investment. "He believes that training is as important as it cannot be Omission it improves the performance of individuals, which contributes to an increase production quantity and quality improvement at the lowest cost, as it is it leads to keep pace with the rapid technological developments emerging, and improves the organization's services and delivery method the good or service, where training matters reduces the possibility of accidents between employees and works. On developing job stability so that the worker feels that he is part of the organization, which increases the satisfaction of both parties.

3. Enablement: As for employees with performance goals, they believe that competence is a steady state and people either possess it as a talent or do not possess it, so they choose easy tasks that increase their chances towards performing these tasks and move away from tasks that bring them failure, as they respond to easy tasks with a sense of pride and see the effort as a sign of low efficiency, as they use strategies that encourage surface learning and memorization of topics such as repetition and memorization and assess their performance relative to their comparison with colleagues, so they are driven externally to learn. [27], adds that there is a close relationship between the traits of individuals and their motivation to work, as they have shown that there is a large group of traits estimated that were classified as related to the motivation of learning in job, and the results of their research indicated that success or failure to learn is closely related to extroversion and awareness; the characteristics of individuals have a strong influence on their motivation and this is 
confirmed by what Murphy referred to in [28], considering that motivation is the actions of living things partially determined by their nature or internal structure, as for behaviors the emotions of individuals are a consequence of the events that motivate them, so they want to without behaviors and emotions, of course, depend on the type of stimuli and their prior experience with them. Behaviors and emotions are relative in response to events related to motivation or the result of a recall of mental processes [29].

\section{Opportunity}

The team of this research attempt to show that the environment and the characteristics of the individual interact to push them towards or away from work in light of what the individual feels on the one hand, and the facilities or difficulties provided by the environment on the other hand. As mentioned previously, opportunity refer to the factors that lie outside the individual that make the behavior possible. The following three factors will work intensively to contribute to implement the change behavior plan

4. Education: Participants had a good chance of learning activities which aimed to select and adapt new contexts to improve their self-control. [30], have been confirmed organizational learning is the process of the flow of knowledge from individual perception and action to the store of knowledge embodied in practices regulatory, practically, participants have been received variance of information related to self-control, patience, discipline, and regulations and new techniques to empower their abilities of communication and solve problem. Several workshops and materials including books and videos was delivered to participants over 12 weeks. Contact groups (Groupware:) is a program that helps workers to communicate as a team that is part of the organization's infrastructure prepares the organization to complete its work with high quality,

5. Persuasion: the team exert acceptable influence on convictions efforts to change them in whole or in part by presenting the facts with clear and acceptable evidence. It is clear from the previous definitions that persuasion is a branch of mastery of communication skills and mastery of the arts of dialogue and etiquette. In order to persuade the people, it is necessary to have credibility: in promises, news and evaluation. As well as ability to use several methods of persuasion: word, article, logic, emotion, scientific, cultural and knowledge level. Commitment to the principles and convictions that he wants to convince others of it. The message must be clear and unambiguous, so that the audience of the addressees can understand it identically. The emergence of its goal without the hassle of searching for it. Arranged logically with an emphasis on evidence and the goal.

6. Incentivization: all internal and external factors that contribute to stirring the behavior of the individual and increasing the human desire to work and diligence and giving in order to achieve certain goals. incentives as the external temptations and encouraging factors that lead the individual to work harder; they are given due to the individual's excellent performance since he/she will work harder and produce more effectively when he feels satisfied in the institution. In addition to this incentive can also, be defined as the consideration of the excellent performance, assuming that the salary is enough to make the worker appreciate the value of the job that also satisfies his basic needs in life [31]. Participants has been exposure to the important thing, they should respect the 
undertaking and fulfilling of the obligations. When they enters into any contract, he should honor it until the end. This is the demand of the faith that when a man talks of any enterprise, he should have the intention of taking it to completion [5]. The Quran says, "O you who believed, fulfill [all] contracts". And: “ ... fulfill [every] commitment. Indeed, the commitment is ever [that about which one will be] questioned" (17:34) [32].

Incentives normally contribute to increase employee's productivity and take two shapes, material and moral incentives or financial and non-financial incentives. Incentives, which are extrinsic motivators, is to increase intrinsic motivation to achieve long-term success [32]. Studies have shown that people with high intrinsic motivation are more successful and report more happiness in their careers longterm. There is no one type of incentives can lead to motivate people to work in a certain way. Rewards, promises, morale rewards and promotion are working together to make employees desire to behave in certain way [33]. This project adopts the morale incentives and focus on the promises they will get in their job if they become more string internally. Self-control as we convinced the participants will build their wellbeing and inner stability and increase their passion to perform well.

\section{Capability}

Capability is the quality or state of being capable to do something with assist of possessed skills and self-power. It means ability and includes the following synonyms: susceptibility, ability, efficiency, proficiency, skill, understanding, treatment and change of the surrounding environment, language and thinking, all of which promote a basic meaning, which is the effectiveness of effective interaction with the environment [34].

A problem-solving strategy is a strategy that has an adaptive function that affects an individual's emotional response, causing significant changes in emotions, which in turn are reflected in his behavior [35]. The importance of the problem-solving strategy through its assistance lies in improving analytical capabilities and learning facts, skills and concepts and transferring them to new situations. The problemsolving strategy works to enhance the emotional development and improve human 'motivation towards learning. [36], in their study demonstrating that motivation is related to problem-solving behavior with both mathematical and applied types. To ensure the effective application of the interventions, we proposed several tips to exposure the participants to the proper influence.

7. Restrictions: An interrelated dialectical relationship between concepts of public behavior, behavioral discipline, public morality, self-compliance, and fear of law or punishment, No one is safe from committing mistakes or negative behavioral behaviors whose severity of rejection varies here or there, and most of them denote and reflect a person's awareness, maturity, and commitment, and there are many laws that teach people disciplined behavior, or that is consistent with the community system, or its social institutions. To encourage employees to give up bad behavior and adopt desired behavior, it is necessary to let them aware of the consequences of not following the rules. Connect with policies, ensure safety of employees in job and certify they are complain with organizational vision. 
8. Environmental restructuring: it refers to reshaping the business workplaces, to make sure that all spaces and products are created or modified in a proper way to help people engage in the new behavior and be abandon from the undesired one.

9. Modelling: as Michi stated that, modelling could be a method used in training, but we use the term more specifically to refer to using our propensity to imitate as a motivational device. Also, providing an example for people to aspire to or imitate [13]. Team of this research, used the Role Model (Qodwah Hasanah) as an experienced model to promote the capabilities. [37], suggested a virtuecentric and moral approach to leadership, explicating Qur'anic emphasis on the role-modelling aspects of the character Muhammad (khuluqin azeem). Thus, team encouraged a beneficial substitute to the transactional, self-centered model and the value neutral transformational approach. Provide the participants with stories of good example from history and current successful stories to prompt their practical wisdom and virtues to ensure behavioral ethicality based on the 'qualities' of truthfulness and integrity, trustworthiness, justice, benevolence, humility, kindness and patience (sabr). Further, the Qur'an emphasizes the modelling dimension of Muhammad's character-centric exemplar [38], [39].

The process of doing the nine patterns of behavioral change model as suggested by [13] took 2 months to ensure application of all requirement of the three dimensions. The step later was to measure the level of self-control to observe any advance has been achieved. The same process of measuring the self-control as used in the initial stage. Mean-level change was assessed by comparing mean of self-control scores at Time 1 (Week 1 ) with mean scores at Time 2 (week 10). To determine the degree to which the mean-level changes held for each participant in our study, we also assessed individual-level personality change. We classified people as having decreased, increased, or stayed the same on each dimension, based on the Reliable Change index [40]. Table (3) reports the means and standard deviations for each dimension at the beginning and end of college, as well as the standardized mean difference between Week 1 and week 10 . 
Table 3

the means and standard deviations for each dimension

\begin{tabular}{|lllll|}
\hline & Item Statement & $\mathrm{m}$ & SD & Level \\
\hline 1 & I am good at resisting temptation. & 4.18 & 0.69 & High \\
\hline 2 & I have a hard time breaking bad habits. & 2.24 & .62 & \\
\hline 3 & I say inappropriate things. & 1.23 & 0.95 & Good \\
\hline 4 & I do certain things that are bad for me, if they are fun. & 2.25 & 1.21 & Good \\
\hline 5 & I wish I had more self-discipline. & 3.85 & 0.89 & Good \\
\hline 6 & Pleasure and fun sometimes keep me from getting work done. & 3.54 & 0.80 & Good \\
\hline 7 & I have trouble concentrating. & 2.68 & 0.67 & Moderate \\
\hline 8 & I am able to work effectively toward long-term goals. & 4.05 & 1.28 & High \\
\hline 9 & $\begin{array}{l}\text { Sometimes I can't stop myself from doing something, even if I } \\
\text { know it is wrong. }\end{array}$ & 2.69 & 0.69 & Good \\
\hline 11 & I refuse things that are bad for me. & 3.92 & 0.44 & Good \\
\hline 12 & People would say that I have iron self-discipline. & 3.81 & 0.54 & Good \\
\hline 13 & I often act without thinking through all the alternatives. & 3.49 & 0.60 & Good \\
\hline
\end{tabular}

\section{Discussion}

The revealed results indicate that, there is no decrease of self-control happened with all participants but there were some cases they couldn't make any further development of their behavior and they forming minor number $5 \%$ only.

The initial collected data of self-control level was revealed a significant low level of self-control as reported by the employees. Therefore, it was motivating the research team that this work environment is promising to enable them work experimentally to work hand to hand to improve this situation. Selfcontrol as explained by [41] refers to the will power or strength of will and it is clearly a form of intentional control over behavior. Thus, to control behavior particularly those include temptation and people curious to act in line with their desires even they are harm, clearly people need stronger power and readiness to defeat that temptation power. We found also that people with low on self-control testified an outstanding range of unhappy and undesirable outcomes in performing job, social life, personal adjustment, and emotional patterns.

The hard working with nine aspects of behavioral change model as suggested by [13], took two months to ensure application of all requirement of the three dimensions (motivation, capability and opportunity). 
The first aspect the team of this research work on is motivation which is defined as a complex process of arousal that strengthens and guides behavior. [42], defined it as the general tendency to reach certain goals. Motivation is the force that drives behavior and works to continue it and direct it towards the goal; also, motivation is a process, or a series of operations that excite, target, maintain, and ultimately stop target-oriented behavior. Thus, it was the most important and difficult part to work on in order to elevate the level of employee motivation particularly the part of external motivation which need too much effort to be done from the leadership of the hospital which we or the employee can't control it. The importance of motivation is also evident in increasing employee's ability to solve problems, as many daily problems are affected by the extent to which an individual has the adaptive skills to deal with life changes. Moreover, internal factor that raises and directs the behavior of the individual, and this motivation includes two important factors: the first is to push the individual towards work, and the second is the cessation of this motivation when satisfied in the event of reaching the goal or obtaining the reward and feeling satisfied.

The importance of motivation is evident from the work point of view through its effect on employees developing and behavior, as there is no learning without motivation; the goal of learning is a motivation, and many psychologists believe that the main reasons for the existence of individual differences in achievement among learners are due to the variation in the level of motivation they have. There is also a close correlation between behavior and motives; behind the behavior lies a group of motives that in turn provoke the behavior in certain circumstances and work to perpetuate it until it ends to a specific goal: gratification and rebalancing.

As the issue of motivation occupies an important position in the field of workplace learning and education, the level of employee motivation for learning is affected by their emotional-behavioral features, which makes it a source of concern for interest. Their emotional-behavioral traits and this has become an imperative imposed by the low level of work achievement of employee. Therefore, developing employee motivation for learning requires us as trainers to recognize their emotional-behavioral traits and invent strategies to help the field of learning and education, which has become a fundamental issue in the field of developing the ability of employee and developing their motivation to learn; for the purposes of this study, the impact of training on the problem-solving strategy based on emotional-behavioral features in developing the motivation of learning will be indicated.

The employees know that the behavior is directed towards a specific goal, as individuals set goals and then direct their behaviors towards those goals, and motivation determines the quality of those goals that people seek. Thus, it affects the goals that the employees choose. Furthermore, Muslims seek selfsatisfaction because they believe that Allah is watching over them [5]. Therefore, it determines the effort and energy that the learners exert to achieve the goal; the motivation increases the amount of effort and energy that the employees exert in any task, and determines the extent to which the employee pursues the mission with enthusiasm and sincerity on the one hand or with weakness and indifference on the other hand. 
Encouragement and motivation are determining the degree to which employees initiate their activities independently and persevere for the sake of completing these activities. They start the task and persist in completing it and completing it even if someone interrupts them while performing this task or they feel frustrated. Encourages the processing of information in a way that achieves the goal, because employees motivated by pay more attention, and this attention is necessary in order to facilitate the entry of information into the working memory and long-term memory in the human brain, when employees motivated by inquire about a certain profession, they tend to understand the material in a way good instead of trying to memorize it without understanding, these are questions or inquiries in order to clarify a certain thing or to practice more of the task. It has a reinforcing function, where motivation determines the thing that enhances employees, from the point of view of behaviorists. The more employees are motivated to achieve work success, the prouder they are of having excellent assessment, and they will be upset if they get a low score. Improving performance, as motivation leads to improved performance due to the above factors, and here we can say that the greater the motivation among employees, the greater the employees work achievement.

We focused on increasing the motivation for achievement as it is influenced by several factors, including cultural values, social role, training processes and interaction between group members. Therefore, achievement motivation is a learned and acquired matter that varies from one person to another according to different situations. [43], mentioned three factors that determine the learner's ability to achieve, which is the motivation for achieving success, the probability of success and the value of the motivator of success. Therefore, we intended to lift the participants' desire to success and it was very obvious we noticed their energy of implementation increasing gradually day after day.

Training elements were designed and focused on developing particular skills which is improving the selfcontrol. It is a form of self-control training and not a suppression of feelings at all. Let them try to look at what surprises them and keep quiet. Also, we try to bump into something and bury their feelings without rushing. We let them try to face something that disturbs anybody or irritates them and turns away from it without reacting. We monitor them and encourage them to be patient, and not show anything of chest tightness or anger. We let them to write down the situations that went through them in the same day that you actually managed to fully control themselves. For example, it was $50 \%$, and then on the second day, it would be at least $60 \%$ until it reaches $90 \%$ within a week. The participants realized and convinced to have the power of self-control at the end that the self-control as personal behavior is a personal decision. Thus, people once take that decision to make his behavior within the area of control the person will take any responsibilities and actions to reflect the positive reaction.

Another procedure, we let everybody watching one of his colleagues and register any remarks he thinks it should be considered. So, in this case everyone knows he is observed and his reactions will be noticed. Despite the process of observation, bring stress and anxiety [44]. The frequent anxiety in a monitored organization is generally not whether monitoring should take place, but how it should be performed, how the information should be utilized, and how feedback should be communicated to all individuals in the organization.

Page $17 / 25$ 
In behavior modification programs and their implementation, the model of change is very important, it include a set of general steps that these plans should contain. They are: Components of the behavior modification plan. Determining the target behavior. Defining the target behavior. Measuring the target behavior. Functional analysis of the behavior. Designing the treatment plan. Implementing the treatment plan. Evaluating the effectiveness of the treatment program. Summarizing the results and writing the report.

In parallel, it is worth to be mentioned that the HR department worked in equivalent and they were keen to do their responsibility by concentrating on warming the ability to have the real motivation to change behavior and increase their self-control. They believe in the opportunity of restructuring the human behavior to cope with the hospital strategy of healing people. Workplace environment will have chance to be restructure when people belief in the employee and gift them the trust and confident they need to ensure change. Behavior modification is a form of therapy that aims to achieve changes in the behavior of an individual that makes the lives of those around him more positive and effective [45]. Such as positive reinforcement or empowerment lead simply to amend the type of behavior targeted.

\section{Conclusion}

Self-control is individual internal power that enable a person to bring actions to consist with ethics and appear more reasonable. This empirical study aimed to achieve four objectives as the following: identify the level of employee's self-control, arrange interventions and have development plan using change behavior model including few courses and workshops to ensure that employees learn new techniques enable them to improve their self-control. This process took several weeks until they understand and apply what they learn in a course of action, changing a desired behavior needs planned change behavior and it took long time therefore, this study aims also to pave the way to translate the theory to practice by examining the change model to ensure the development of self-control behavior. In addition, to suggest a fruitful step that make useful recommendations in designing and applying change intervention and reuse the measurement tool to re-assess the participant's self-control to estimate their level of self-control post the process of development.

The study used a combination of models to change human behavior. The science of behavior modification is one of the most important applied sciences in the field of dealing with human behavior, as behavior modification is currently used extensively in various fields that are not limited to education but extend to the judiciary, sports and even politics. And behavior modification has evolved in the recent period and has become more interested in the cognitive behavioral aspect. Behavior modification is a structure-specific learning in which the individual learns new skills and new behavior, reduces unwanted responses and habits, and the student's motivation for the desired change increases.

The behavior modification strategy passes according to specific steps and procedures that are followed to implement the behavior change program. The first step was determining the behavior intended to modify or change. This is intended to define the behavior to be modified accurately so that it can be 
observed, measured and evaluated. Define and measure targeted behavior procedurally. This means a procedural definition and a clear behavioral formulation of the behavior that we want to remedy so that it can be observed and measured. This is intended to define the conditions and situations that precede the occurrence of the behavior and that may constitute a factor in its occurrence, as well as to determine the results or responses resulting from this behavior. The goal to be reached must be clearly defined, that is to improve human self-control, by completion of the behavior modification program and this is called behavioral goals. This means choosing the appropriate strategy, procedures and techniques to modify behavior. The effectiveness of any program is determined by the extent to which it achieves its goals, and accordingly, we judge the behavior modification program by how close it is to achieving the desired goals and formulating it in a procedural way, whether the goal is to support desired behavior, shape new behavior, or extinguish unwanted behavior.

The results of this study are inspiring that identifying behavior in workplace need for improvement by design a plan and work to achieve that plan with obvious interventions. We believe that self-control produces positive benefits to the employees and organization and suggests that the benefits of selfcontrol are worth serious consideration. We found that people with high self-control got better well-being in job, were better adjusted, had better interpersonal skills and better interpersonal relationships, and had more optimal emotional lives than other people.

This study has limitations related to the longitudinal method as the selective factors in the original sample include individuals who agreed to participate in a research of a special nature to continue for several months were chosen according to control factors and are not randomly selected. In this case, it is difficult to generalize the results of such longitudinal research to the original community. The effect of repeating the observations: the repeated practice of testing and increasing familiarity with the research team, and autism in one of the groups for a relatively long period of time may all affect the examiners' performance in the tests, their directions and their motives. Future studies can generalize the change in behavior to new situations in a natural environment or living situations. They can identify another behavior and apply this design used in this study to test and modify undesired behavior that may perhaps contribute to enhance employees' performance.

Finally, this study adds to the body of knowledge by developing and validating a new model in change human behavior i.e. the change behavior stages (CBS) model. Practically, this study is one of its kind to apply the Brief Self Control Scale (BSCS) and the Behavioral Change Wheel (BCW) in health sector in the Middle East. The BCW has been also confirmed as a "valid" and "reliable" instrument that can be utilized by future researchers to improve human behavior in organizations.

\section{Abbreviations}

TTM, The Transtheoretical Model

PA, Physical Activity 
BSCS, Brief Self-Control Scale

BCW, Behavioral Change Wheel

CBS, Change Behavior Stages

SPSS, Statistical Package for the Social Sciences

\section{Declarations}

Ethics approval and consent to participate

The participants were given permission to involve them in this research and keep their identity anonymous according to the agreement between them and researchers. In addition, this study ethically approved by the Research, Innovation and Research Ethics Committee in the ASU university in Bahrain.

\section{Consent for publication}

Not applicable

\section{Availability of data and materials}

The datasets used and/or analyzed during the current study are available from the corresponding author on reasonable request.

Competing interests

The authors declare that they have no competing interests

Funding

Not applicable

\section{Acknowledgements}

We would like to thank the HR department, patient registration department and patient reception section at $\mathrm{KH}$ Hospital, Bahrain for their valuable help and assistance during the period of the experimental study i.e. from November 2019 to January 2020. Special thanks are also due to the 64 anonymous participants who voluntarily accepted to be involved in this research effort.

Author details

${ }^{1}$ Associate professor at College of Administrative Sciences, Applied Science University (ASU), Kingdom of Bahrain. 
${ }^{2}$ Professor at College of Administrative Sciences, Applied Science University (ASU), Kingdom of Bahrain.

${ }^{3}$ Professor of MIS, Vice President of Academic Affair, University of Modern Science, Dubai, United Arab Emirates.

\section{Authors' contributions}

SA and MA conceived the study, designed the measures, supervised the systematic review, supervised the analyses and drafted the write-up. M N undertook the systematic review, performed the coding and commented on the write-up. All authors read and approved the final manuscript.

\section{References}

1. Abdeldayem, Marwan M, Aldulaimi SH. Trends of Global Fintech Education Practices and the GCC Perspective. International Journal of Advanced Science Technology. 2020;29(3):7150-63.

2. Bandura A. Self-efficacy. The exercise of control. New York: W.H. Freeman and Company. Information on Self-Efficacy: A Community of Scholars: Emory University, Division of Educational Studies; 1997.

3. Kotter JP, Cohen DS. (2012). The heart of change: Real-life stories of how people change their organizations. Harvard Business Press.

4. Goleman D. Emotional intelligence. New York: Bantam; 1995.

5. Aldulaimi S. "Fundamental Islamic perspective of work ethics". Journal of Islamic Accounting Business Research. 2016;7 No(1):59-76. https://doi.org/10.1108/JIABR-02-2014-0006.

6. McGonigal K. (2016). The upside of stress: Why stress is good for you, and how to get good at it. Penguin.

7. Prochaska J, DiClemente $\mathrm{C}$. Stages and processes of self-change in smoking: toward an integrative model of change. J Consult Clin Psychol. 1983;5:390-5.

8. Han H, Gabriel KP, Kohl III, H. W. (2017). Application of the transtheoretical model to sedentary behaviors and its association with physical activity status. PloS one, 12(4).

9. Prochaska JO, Velicer WF. The transtheoretical model of health behavior change. American journal of health promotion. 1997;12(1):38-48.

10. Ajzen I. From intentions to actions: A theory of planned behavior. In: Kuhl J, Beckman J, editors. Action-control: From cognition to behavior. Heidelberg: Springer; 1985. pp. 11-39.

11. Ajzen I. The theory of planned behavior. Organ Behav Hum Decis Process. 1991;50:179-211.

12. Lewin K. Group decision and social change. Readings in social psychology. 1947;3(1):197-211.

13. Michie S, Van Stralen MM, West R. The XXXehavior change wheel: a new method for XXXehaviorXXXizing and designing XXXehavior change interventions. Implementation science. 2011;6(1):42.

14. Abdeldayem MM, Dulaimi SHA. Privatisation And Financial Performance In Egypt Since 1991. Asian Economic Financial Review. 2019;9(4):461. 
15. Aldulaimi SH, Abdeldayem. (2019). How Changes In Leadership Behaviour And Management Influence Sustainable Higher Education In Bahrain.

16. Burr JA, Nesselroade JR. (1990). Change measurement. In Statistical methods in longitudinal research (pp. 3-34). Academic Press.

17. Hertzog C. (1996). Research design in studies of aging and cognition.

18. Chan D. (1998). Functional relations among constructs in the same content domain at different levels of analysis: A typology of composition models. Journal of applied psycholo.

19. Tangney JP, Baumeister RF, Boone AL. High self-control predicts good adjustment, less pathology, better grades, and interpersonal success. Journal of personality. 2004;72(2):271-324.

20. Aldulaimi SH, Abdeldayem MM. The economic value of time in Arab culture: New evidence using Zimbardo Time Perspective Inventory (ZTPI). American Journal of Social Sciences Humanities. 2018;3(1):63-72.

21. Mook D (1995), Motivation: The Organization of Action, New York; London WWNorton, Companygy. 83(2), 234.

22. Turner LA, Johnson B. A model of mastery motivation for at-risk preschoolers. Journal of educational psychology. 2003;95(3):495.

23. Burns RB, Dobson CB. The self-concept. In: Introductory Psychology. Dordrecht: Springer; 1984. pp. 473-505.

24. Crocker LD, Heller W, Warren SL, O'Hare AJ, Infantolino ZP, Miller GA. Relationships among cognition, emotion, and motivation: implications for intervention and neuroplasticity in psychopathology. Front Hum Neurosci. 2013;7:261.

25. Feldman SS, Elliott GR, editors. (1990). At the threshold: The developing adolescent. Harvard University Press.

26. Abou-Saleh MT. Dual diagnosis: management within a psychosocial context. Adv Psychiatr Treat. 2004;10(5):352-60.

27. De Raad B, Schouwenburg HC. Personality in learning and education: A review. European Journal of personality. 1996;10(5):303-36.

28. Cofer CN, Appley MH. (1968). Motivation: theory and research (No. 159.4 C6)..

29. Carlson NR, Martin GN, Buskist W. (2004). Psychology (2nd European edn.).

30. Hamilton BA, Scandura TA. E-Mentoring:: Implications for organizational learning and development in a wired world. Org Dyn. 2003;31(4):388-402.

31. Wynter-Palmer JE. Is the Use of Short-Term Incentives Good Organization Strategy? Compensation Benefits Review. 2012;44(5):254-65.

32. Musab MM. Elements Constituting the Best Practice of Shari'ah Governance in Islamic Finance. Bait Al-Mashura Journal. 2015;issue2:p18.

33. Ziaurrahman M. (2019). Tradable and Non-Tradable Right from Islamic Law of Contracts Perspective, Bait Al-Mashura Journal. Issue 11. 
34. Farnham-Diggory S. Cognitive processes in education: A psychological preparation for teaching and curriculum development (No. 04; LB1053, F3.). New York: Harper \& Row; 1972.

35. ZAWAWI D, Tsang D. Understanding emotional intelligence in a diverse society. International Journal of Business Management Studies. 2009;1(2):27-38.

36. Vermeer HJ, Boekaerts M, Seegers G. Motivational and gender differences: Sixth-grade students' mathematical problem-solving behavior. Journal of educational psychology. 2000;92(2):308.

37. Beekun R. (2008), "Is Muhammad (p) a Transformational Leader?", keynote address to the Conference on Islamic Management and Leadership Ethics, May 20-21, Kuala Lumpur.

38. Aldulaimi SH. (2019). Leadership Concept and Constructs in Arabic Philosophy. Journal of Economic Cooperation \& Development, 40(2).

39. Mechkour A, Lotfi S. (2018). Moroccan of Compliance Shariah for Framework Legal Banks Islamic, Bait Al-Mashura Journal, issue 9 p284.

40. Christensen L, Mendoza JL. A method of assessing change in a single subject: an alteration of the RC index. Behavior erapy. 1986;17:305-8.

41. Henden E. What is self-control? Philosophical Psychology. 2008;21(1):69-90.

42. Slavin RE. Quality, appropriateness, incentive, and time: A model of instructional effectiveness. International Journal of Educational Research. 1994;21(2):141-57.

43. Atkinson JW. (1958). Motives in fantasy, action, and society: A method of assessment and study.

44. Griffin RW. Management. 9th ed. Lewiston: Houghton Mifflin; 2008.

45. Al-khrabsheh AA, Muttar AK, Mahdi OR, Nassar IA, AI S, Abdullah II, P. A. H. B. (2018). The Impact of Organisational Factors on Organizational Commitment at the Arab Bank in Jordan. Asian Social Science, 14(7).

\section{Figures}




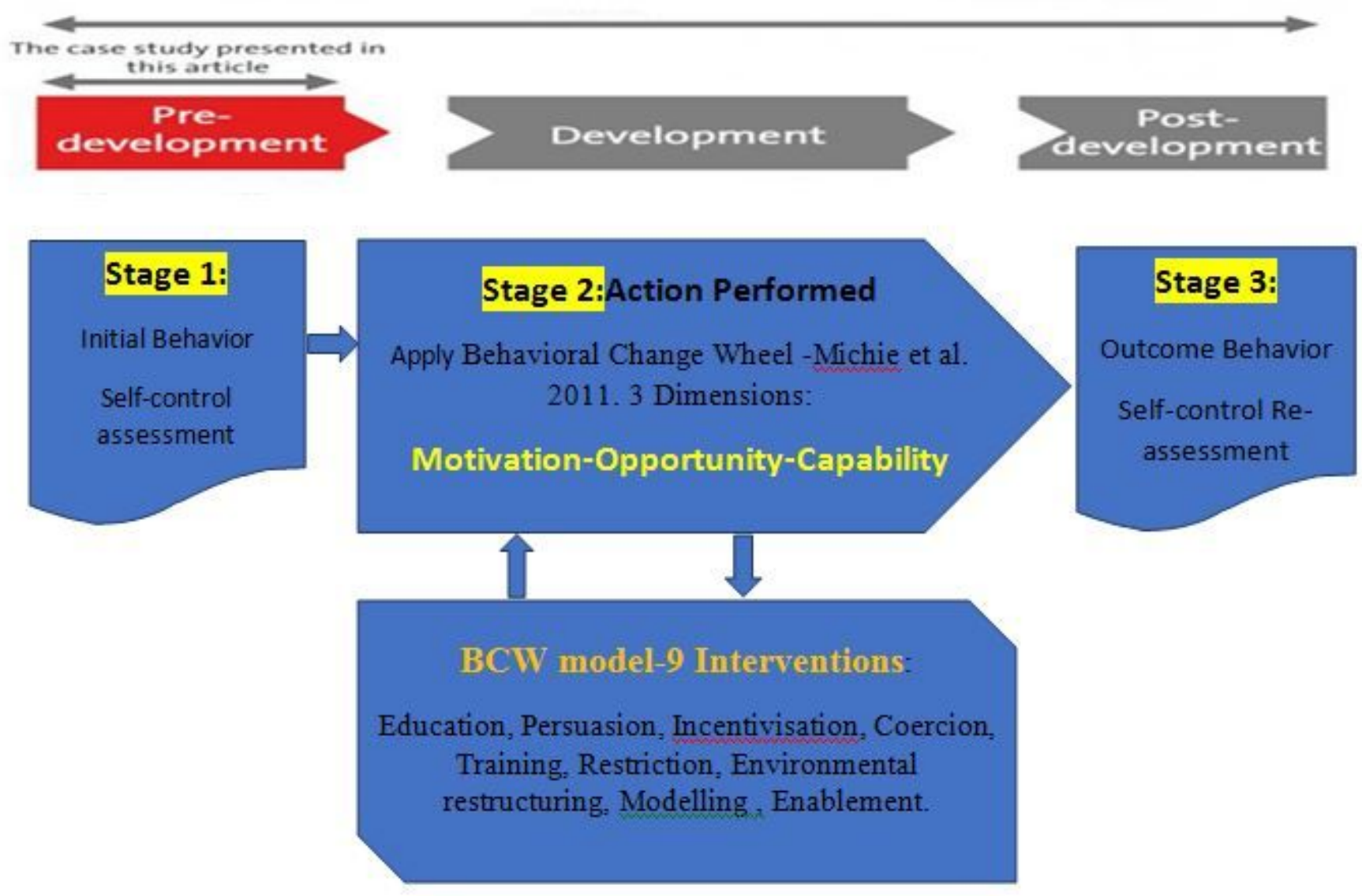

\section{Figure 1}

the change behavior stages (CBS) model as a conceptual framework of the study Source: developed by authors 


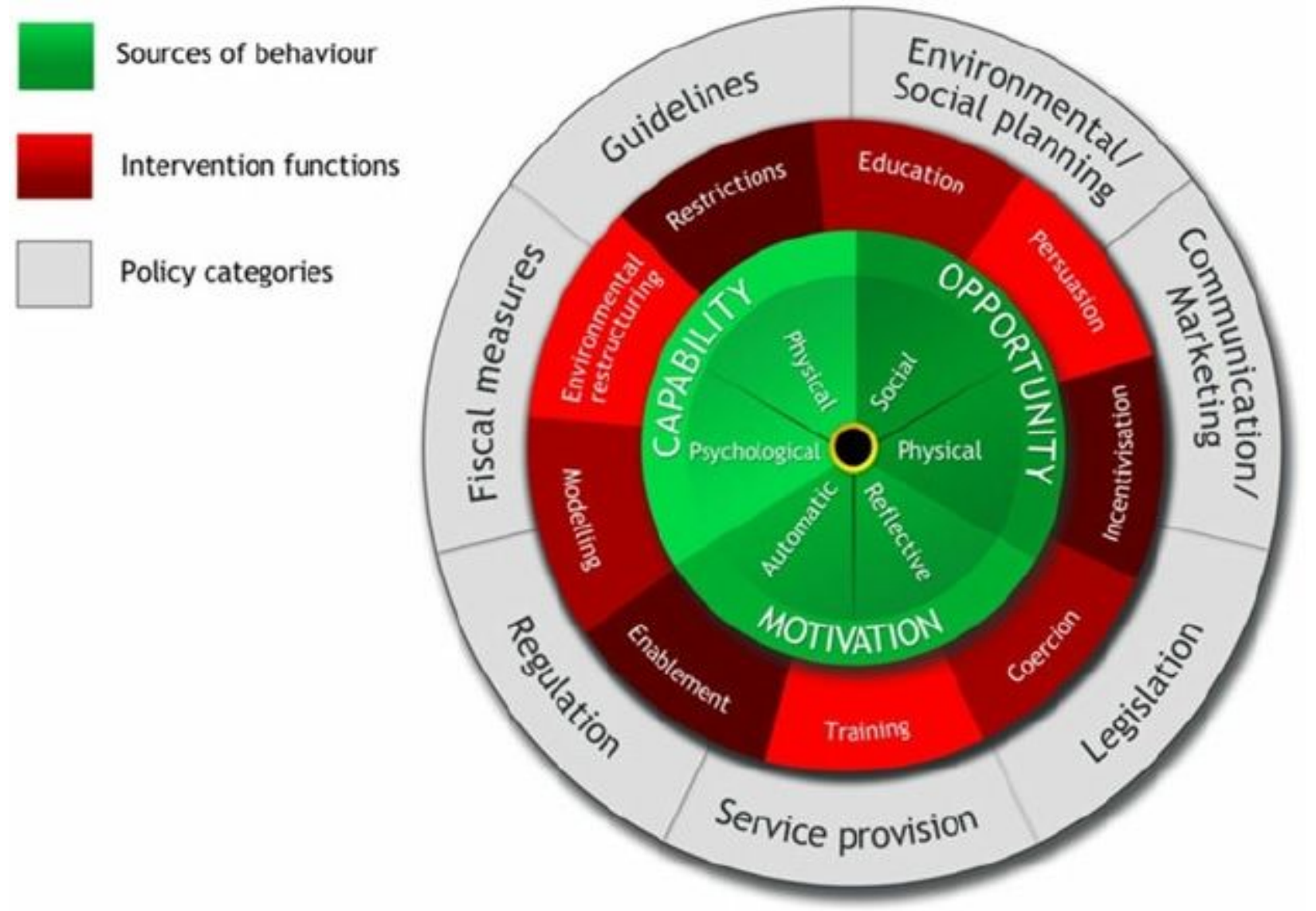

Figure 2

the Behavior Change Wheel (BCW) Model for implementing change behavior Sourse: Michie(2011)[13] 